\title{
Exposure to Polybrominated Diphenyl Ethers in the Sixth Total Diet Study - China, 2016-2019
}

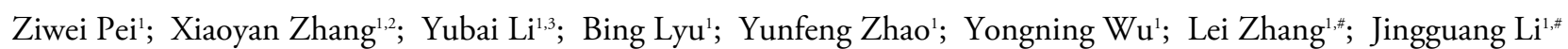

\section{Summary \\ What is already known about this topic? \\ Polybrominated diphenyl ethers (PBDEs) were widely used in many industrial and commercial materials as flame retardants, and its related exposure threatens human health. \\ What is added by this report? \\ The Sixth Total Diet Study (TDS) indicated that the dietary intake of PBDEs was unlikely to pose significant health risks for the general Chinese people using the margin of exposure (MOE) approach recommended by the European Food Safety Authority (EFSA). \\ What are the implications for public health practice? \\ This study highlights the necessity of continuous national monitoring of the dietary intake and strict legislation of PBDEs in China.}

Polybrominated diphenyl ethers (PBDEs) are widely used in many industrial and commercial materials as a class of brominated flame retardants (BFRs), and its related exposure threatens human health (1). Certain PBDEs have been banned worldwide, and the congeners in commercial penta-BDE mixtures, octa$\mathrm{BDE}$ mixtures, and deca-BDE mixtures - including BDE-47, -99, -153, -154, -175, -183, and -209were listed as persistent organic pollutants (POPs) by the Stockholm Convention (2-3).

The details of the Total Diet Study (TDS) are described in the Foreword of this issue (4), and the measurement of PBDEs was detailed elsewhere (5-6). PBDEs were detectable in all samples. The concentrations of PBDEs varied greatly among various food groups as depicted in Table 1. The levels of $\sum_{7} \mathrm{PBDEs}$, the summation of $7 \mathrm{PBDE}$ congeners, were dominated by aquatic products with $39.85 \pm 33.46 \mathrm{pg} / \mathrm{g}$ fresh weight (mean \pm standard deviation), followed by meats and eggs with concentrations of $29.75 \pm 32.73$ $\mathrm{pg} / \mathrm{g}$ fresh weight and $22.19 \pm 31.96 \mathrm{pg} / \mathrm{g}$ fresh weight, respectively. Lower concentrations were observed in dairy products and other plant origin food samples $(P<0.05)$, which was consistent with other studies $(7)$. Dietary intake of $\sum_{7} \mathrm{PBDEs}$ for Chinese adults was $0.24 \pm 0.38 \mathrm{ng} / \mathrm{kg}$ body weight per day (mean \pm standard deviation) with a range of $0.02-1.96 \mathrm{ng} / \mathrm{kg}$ body weight per day, and the geometric mean was 0.13 $\mathrm{ng} / \mathrm{kg}$ body weight per day. The dietary exposure varied greatly across all regions, as listed in Table 2. Adults from Zhejiang ingested the highest level of $\sum_{7}$ PBDEs at $1.96 \mathrm{ng} / \mathrm{kg}$ body weight per day, followed by those in Inner Mongolia, Guangxi, and Fujian with a dietary intake of $0.39,0.38$, and $0.36 \mathrm{ng} / \mathrm{kg}$ body weight per day, respectively. Generally, the dietary exposure levels in southeastern and southern coastal regions with more industrialization were relatively high, while the levels in central and western regions with typical agriculture and animal husbandry such as Ningxia, Qinghai, Shaanxi, and Shanxi were relatively low. Risk assessment was conducted using the margin of exposure (MOE) approach, and in this study, a conservative estimate was applied, calculated through dividing the levels of $\Sigma_{7} \mathrm{PBDEs}$ by bench marker dose lower confidence limit 10\% (BMDL10) of BDE-47, 99, and -153 , respectively, applied by the European Food Safety Authority (EFSA). The large MOEs ranging $1.0 \times 10^{3}-1.7 \times 10^{7}$ indicated a low health risk in China.

\section{DISCUSSION}

The dietary exposure levels of PBDEs varied widely among countries and regions, ranging from $0.93 \mathrm{ng} / \mathrm{kg}$ body weight per day in Latvia to $2.9 \mathrm{ng} / \mathrm{kg}$ body weight per day in the United Kingdom (Supplementary Table S1, available in http:// weekly.chinacdc.cn/). The dietary intake level in China was low in comparison to other countries in recent studies, which can be caused by differences in dietary study methods, the origin of samples, or dietary preference. For most regions, meat was the main source of dietary exposure to PBDEs, especially seafood (7). 
TABLE 1. Concentrations of $\sum_{7}$ PBDEs in food categories from the Sixth TDS in China.

\begin{tabular}{ccccccc}
\hline Food group & $\mathbf{N}^{*}$ & Mean $^{\dagger}$ & Geometric mean & Median & Min & Max $^{\S}$ \\
\hline Cereals & 24 & $5.60 \pm 15.18$ & $2.13(0.45,10.14)$ & 2.30 & 0.13 & 102.76 \\
Legumes & 24 & $7.06 \pm 10.68$ & $3.92(1.22,12.62)$ & 3.96 & 0.78 & 44.85 \\
Potatoes & 24 & $9.12 \pm 24.06$ & $3.78(1.19,12.02)$ & 4.28 & 0.33 & 128.04 \\
Meats & 24 & $29.75 \pm 32.73$ & $21.58(9.28,50.16)$ & 19.59 & 4.70 & 165.14 \\
Eggs & 24 & $22.19 \pm 31.96$ & $16.17(6.50,40.27)$ & 15.74 & 3.82 & 206.63 \\
Aquatic products & 24 & $39.85 \pm 33.46$ & $31.42(13.61,72.55)$ & 31.99 & 3.05 & 163.81 \\
Dairy products & 24 & $4.17 \pm 6.12$ & $2.53(0.98,6.53)$ & 2.29 & 0.40 & 31.64 \\
Vegetables & 24 & $8.95 \pm 12.47$ & $4.32(1.03,18.02)$ & 5.34 & 0.09 & 60.95 \\
\hline
\end{tabular}

Note: The unit of mean, GM, median, min, and max are $\mathrm{pg} / \mathrm{g}$ fresh weight.

Abbreviations: PBDEs=polybrominated diphenyl ethers; TDS=Total Diet Study.

* Number of food composites of each food group.

${ }^{\dagger}$ Data are mean \pm standard deviation.

$\S$ Data were geometric mean (+1 geometric standard deviation, -1 geometric standard deviation).

TABLE 2. Estimated dietary exposure to $\sum_{7}$ PBDEs from the Sixth TDS - 24 PLADs, China.

\begin{tabular}{cl}
\hline $\begin{array}{c}\text { Dietary intake range of } \\
\text { PBDEs (ng/kg body weight per day) }\end{array}$ & \multicolumn{1}{c}{ Regions (average dietary exposure to PBDEs) } \\
\hline $0.01-0.09$ & Qinghai (0.09); Shanxi (0.09); Hubei (0.08); Shandong (0.07); Heilongjiang (0.04); Hebei (0.04); \\
$0.10-0.19$ & Henan (0.03); Ningxia (0.02); Shaanxi (0.02) \\
$0.20-0.29$ & Beijing (0.18); Jiangsu (0.13); Jiangxi (0.10) \\
$0.30-0.39$ & Guizhou (0.27); Jilin (0.26); Sichuan (0.25); Liaoning (0.22); Shanghai (0.21); Guangdong (0.20); \\
$>0.39$ & Gansu (0.20); Hunan (0.20) \\
\hline
\end{tabular}

Abbreviations: PBDEs=polybrominated diphenyl ethers; TDS=Total Diet Study; PLADs=provincial-level administrative divisions.

However, in China, the main food sources for PBDEs were meats, cereals, and vegetables contributing $24.4 \%, 23.4 \%$, and $23.2 \%$, followed by aquatic products contributing $12.7 \%$. Plant foods including cereals, vegetables, potatoes, and legumes contributed $55.6 \%$, as depicted in Supplementary Figure S1 (available in http://weekly.chinacdc.cn/). The range of MOEs was notably higher than the threshold reference recommended by the EFSA, indicating very low health risk concern in China.

Figure 1 compares dietary exposures to PBDEs of the Fourth, Fifth, and Sixth TDSs during the period of 2007-2019. In the previous study, there was no statistical differences in dietary exposure between the Fourth and Fifth TDS $(P>0.05)$. Whereas, in the Sixth TDS, the dietary intake level decreased sharply $(P<0.05)$, which was reduced by $65.7 \%$ and $62.9 \%$ compared with the Fourth and Fifth TDS, respectively. In a study modeling of flame retardants in typical urban indoor environments in China during 2010-2030, Li et al. found that there will be a decline of human exposure to PBDEs after 2017 (8). The reduction of PBDEs exposure is likely related to contamination control by China authority. Referring to the list of POPs of Stockholm Convention, the Ministry of Ecology and Environment of the People's Republic of China (MEP) in 2014 announced the ban of the import, export, production, and use of pentaand octa-BDE (9). In addition, there were only two areas, Zhejiang and Inner Mongolia Autonomous Region, where the dietary intakes were increased, especially in Zhejiang where it increased by $243.2 \%$. In view of the large increase, it is necessary to follow-up with increased monitoring in Zhejiang. And, a limitation of this study is not paying attention to the potential health risk of dietary PBDEs of special populations. Moreover, considering the diverse possibilities of exposure for PBDEs - ranging from dust ingestion to dermal absorption to dietary intake - further studies should be conducted to investigate the current burden of PBDE exposure in populations.

Based on the existing toxicological data, the current health risk caused by dietary exposure was still low. The dietary intake level decreased sharply compared with the Fourth and Fifth TDS, thus, continuous national monitoring is necessary to evaluate the time trends and support the legislation of POPs for China and from international conventions. 


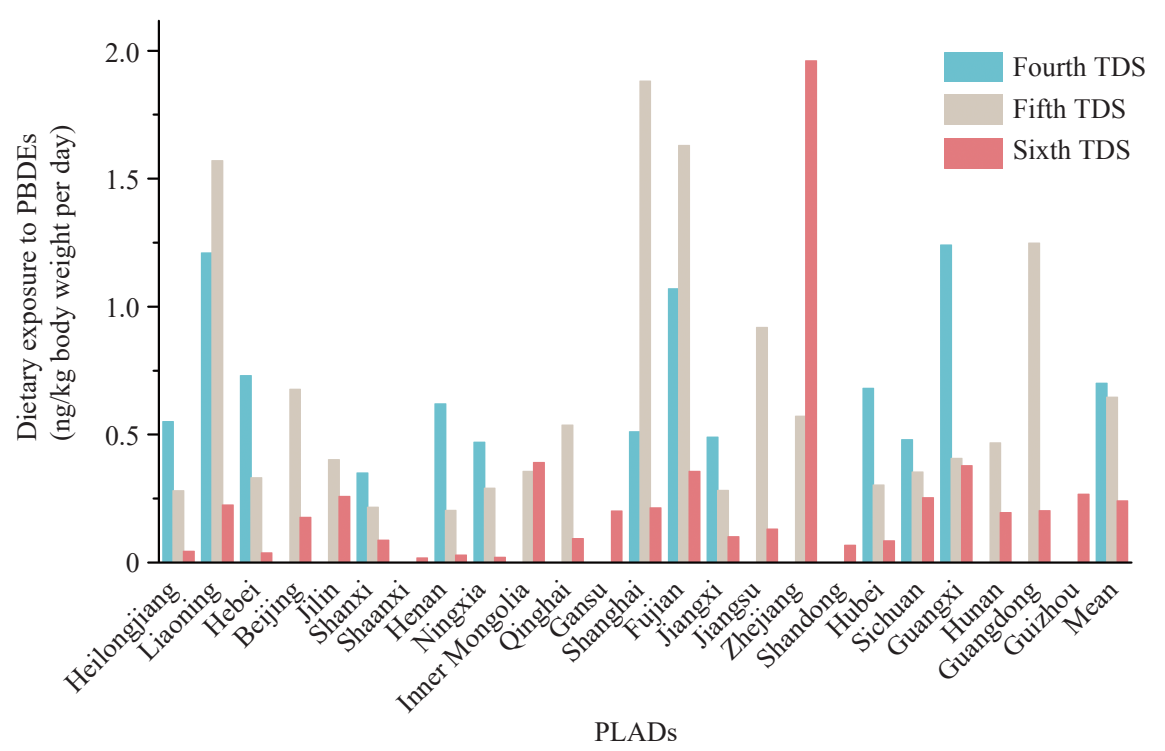

FIGURE 1. Comparison of dietary exposures to $\sum_{7}$ PBDEs among the Fourth, Fifth, and Sixth TDS in China. Abbreviations: PBDEs=polybrominated diphenyl ethers; TDS=Total Diet Sudy; PLADs=provincial-level administrative divisions.

Acknowledgements: The 24 provincial-level CDCs.

Conflicts of interest: No conflicts of interest.

Funding: Supported by the National Key Research and Development Program of China (grant number 2017YFC1600500) and CAMS Innovation Fund for Medical Science (CIFMS 2019-I2M-5-024).

doi: $10.46234 / \mathrm{ccdcw} 2022.041$

* Corresponding authors: Lei Zhang, zhanglei1@cfsa.net.cn; Jingguang Li, lijg@fsa.net.cn.

\footnotetext{
${ }^{1}$ NHC Key Laboratory of Food Safety Risk Assessment, Chinese Academy of Medical Science Research Unit (No. 2019RU014), China National Center for Food Safety Risk Assessment (CFSA), Beijing, China; ${ }^{2}$ Baotou Municipal Bureau of market supervision and Administration, Baotou, Inner Mongolia Autonomous Region, China; ${ }^{3}$ Shanghai Municipal Center for Disease Control and Prevention, Shanghai, China.
}

Submitted: November 18, 2021; Accepted: February 28, 2022

\section{REFERENCES}

1. Wu ZN, He C, Han W, Song J, Li HJ, Zhang YD, et al. Exposure pathways, levels and toxicity of polybrominated diphenyl ethers in humans: a review. Environ Res 2020;187:109531. http://dx.doi.org/10. 1016/j.envres.2020.109531.

2. Stockholm Convention. All POPs Listed in the Stockholm Convention. 2019. http://www.pops.int/TheConvention/ThePOPs/AllPOPs/tabid/
2509/Default.aspx. [2021-8-31].

3. Agency for Toxic Substances and Disease Registry. Toxicological profiles: polybrominated diphenyl ethers (PBDEs). Atlanta: ATSDR. 2011. https: //www.atsdr.cdc.gov/toxprofiledocs/index.html?id=901\&tid=183. [20218-31].

4. Lyu B, Li JG, Wu YN. Characterizing exposome of food contamination and China Total Diet Study: project for improving food safety risk assessment in China. China CDC Wkly 2022;4(9):157 - 60. http://dx. doi.org/10.46234/ccdcw2022.039.

5. Zhang L, Li JG, Zhao YF, Li XW, Wen S, Shen HT, et al. Polybrominated diphenyl ethers (PBDEs) and indicator polychlorinated biphenyls (PCBs) in foods from China: levels, dietary intake, and risk assessment. J Agric Food Chem 2013;61(26):6544 - 51. http://dx.doi. org/10.1021/jf4006565.

6. EFSA Panel on Contaminants in the Food Chain (CONTAM). Scientific opinion on polybrominated diphenyl ethers (PBDEs) in food EFSA J 2011;9(5):2156. http://dx.doi.org/10.2903/j.efsa.2011.2156.

7. Bedi M, Von Goetz N, Ng C. Estimating polybrominated diphenyl ether (PBDE) exposure through seafood consumption in Switzerland using international food trade data. Environ Int 2020;138:105652. http://dx. doi.org/10.1016/j.envint.2020.105652.

8. Li ZW, Zhu Y, Wang D, Zhang XM, Jones KC, Ma JM, et al. Modeling of flame retardants in typical urban indoor environments in China during 2010-2030: influence of policy and decoration and implications for human exposure. Environ Sci Technol 2021;55(17):11745 - 55. http://dx.doi.org/10.1021/acs.est.1c03402.

9. Ministry of Ecology and Environment of the People's Republic of China. Announcements on the Entry into Force of the Amendments to Annexes $\mathrm{A}, \mathrm{B}$ and $\mathrm{C}$ on the Addition of Nine Persistent Organic Pollutants (POPs) and the Amendments to Annexes A on the Addition of Endosultan to the Stockholm Convention on POPs. 2014. http://www. mee.gov.cn $/ \mathrm{gkml} / \mathrm{hbb} / \mathrm{bgg} / 201404 / \mathrm{t} 20140401 \_270007 . h t m$. [2021-831]. 


\section{SUPPLEMENTARY MATERIAL}

SUPPLEMENTARY TABLE S1. Dietary intake levels of PBDEs in other countries and regions.

\begin{tabular}{|c|c|c|c|c|c|c|}
\hline $\begin{array}{l}\text { Countryl } \\
\text { region }\end{array}$ & $\begin{array}{l}\text { Year of } \\
\text { sampling }\end{array}$ & $\begin{array}{l}\text { Dietary intake } \\
\text { (ng/kg body } \\
\text { weight per day) }\end{array}$ & Assessment method & Population & Food groups & $\begin{array}{l}\text { Congeners included } \\
\text { in } \sum \text { PBDE }\end{array}$ \\
\hline Germany (1) & 2005 & 1.2 & $\begin{array}{l}\text { duplicate diet } \\
\text { study/ND=1/2 LOD }\end{array}$ & $\begin{array}{l}\text { The German adults } \\
(n=50)\end{array}$ & & $\begin{array}{l}\text { BDE-47, 99, 153, } \\
154, \text { and } 183\end{array}$ \\
\hline $\begin{array}{l}\text { The United } \\
\text { Kingdom (2) }\end{array}$ & 2011-2012 & 2.9 & $\begin{array}{l}\text { duplicate diet } \\
\text { study/ND }=0\end{array}$ & $\begin{array}{l}\text { The UK adults } \\
(n=20)\end{array}$ & & $\begin{array}{l}\text { BDE-17, } 28,47,49, \\
66,71,77,85,99 \\
100,119,126,138, \\
153,154, \text { and } 183\end{array}$ \\
\hline $\begin{array}{l}\text { The Republic of } \\
\text { Korea (3) }\end{array}$ & 2012-2013 & 1.0 & $\begin{array}{l}\text { market basket } \\
\text { study/ND }=0\end{array}$ & $\begin{array}{l}\text { The Korean } \\
\text { population } \\
(n>33,000)\end{array}$ & $\begin{array}{l}\text { meats, fishes and } \\
\text { shellfishes, eggs, cereals, } \\
\text { vegetables, fruits, dairy } \\
\text { products, fats and } \\
\text { vegetable oils, beverages, } \\
\text { and miscellaneous }\end{array}$ & $\begin{array}{l}\text { BDE-15, 17, 28, 47, } \\
49,66,71,77,85,99, \\
100,119,126,138, \\
153,154,156,183, \\
184,191,196,197, \\
206, \text { and } 207\end{array}$ \\
\hline Latvia (4) & 2016-2019 & 0.93 & $\begin{array}{l}\text { market basket } \\
\text { study/ND=LOD }\end{array}$ & $\begin{array}{l}\text { The Latvian } \\
\text { population }\end{array}$ & $\begin{array}{l}\text { fish and products, meats, } \\
\text { dairy products, cereals, } \\
\text { breads, eggs, vegetable } \\
\text { oils, and sweets }\end{array}$ & $\begin{array}{l}\text { BDE-17, 28, 47, 49, } \\
99,100,138,139, \\
153,154,155, \text { and } \\
183\end{array}$ \\
\hline
\end{tabular}

Abbreviations: PBDEs=polybrominated diphenyl ethers; ND=non-detected value; $L O D=$ limit of detection.

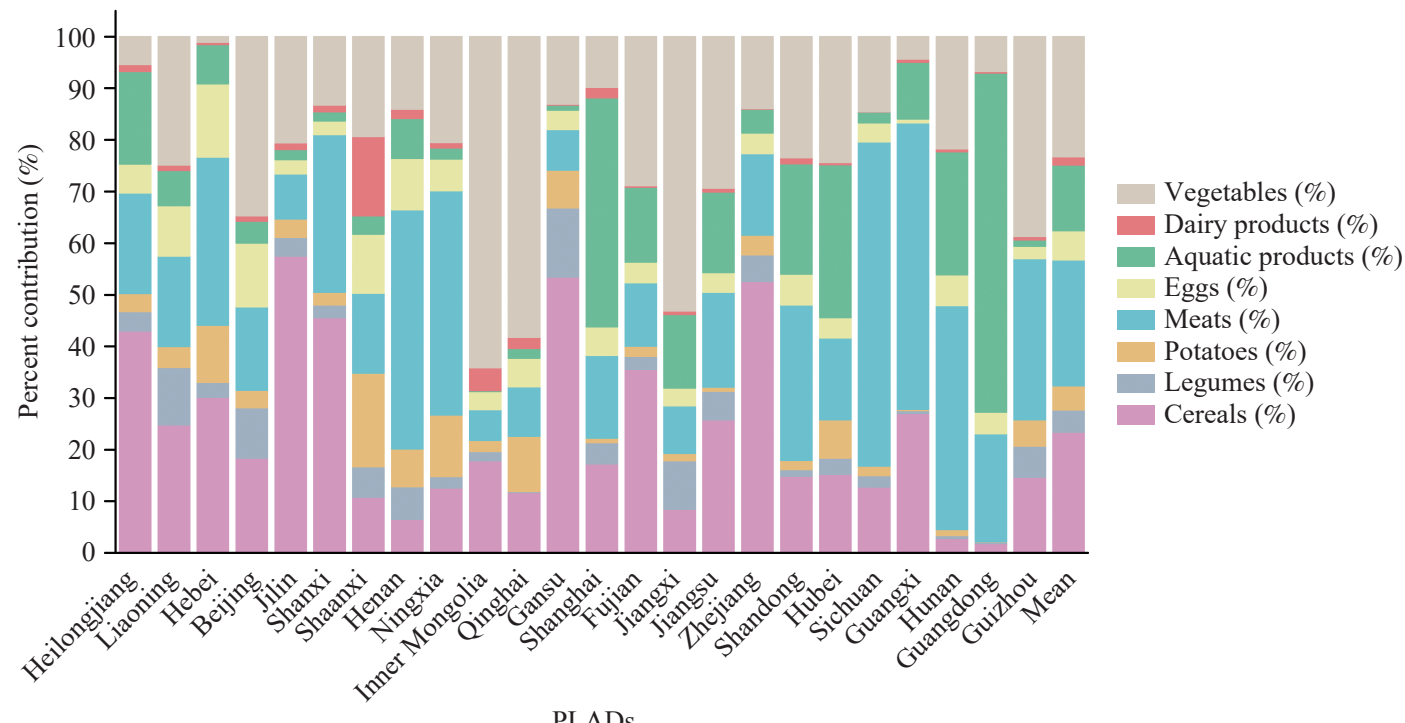

SUPPLEMENTARY FIGURE S1. Percentage contribution of eight food groups to dietary intake of $\sum_{7}$ PBDEs in China. Abbreviations: PBDEs=polybrominated diphenyl ethers; PLADs=provincial-level administrative divisions.

\section{REFERENCES}

1. Fromme H, Körner W, Shahin N, Wanner A, Albrecht M, Boehmer S, et al. Human exposure to polybrominated diphenyl ethers (PBDE), as evidenced by data from a duplicate diet study, indoor air, house dust, and biomonitoring in Germany. Environ Int 2009;35(8):1125 - 35. http://dx.doi.org/10. 1016/j.envint.2009.07.003.

2. Bramwell L, Mortimer D, Rose M, Fernandes A, Harrad S, Pless-Mulloli T. UK dietary exposure to PCDD/Fs, PCBs, PBDD/Fs, PBBs and PBDEs: comparison of results from 24-h duplicate diets and total diet studies. Food Addit Contam Part A 2017;34(1):65 - 77. http://dx.doi.org/10.1080/ 19440049.2016 .1258493$.

3. Nguyen KH, Pyo H, Kim J, Shin E, Chang YS. Exposure of general population to PBDEs: a progressive total diet study in south Korea. Environ Pollut 2014;195:192 - 201. http://dx.doi.org/10.1016/j.envpol.2014.08.030.

4. Zacs D, Perkons I, Abdulajeva E, Pasecnaja E, Bartkiene E, Bartkevics V. Polybrominated diphenyl ethers (PBDEs), hexabromocyclododecanes (HBCDD), dechlorane-related compounds (DRCs), and emerging brominated flame retardants (EBFRs) in foods: the levels, profiles, and dietary intake in Latvia. Sci Total Environ 2021;752:141996. http://dx.doi.org/10.1016/j.scitotenv.2020.141996. 